\title{
7th Bondexpo und 32nd Motek: positive feedback from organiser
}

E air organiser P.E. Schall gives a very and the 32nd Motek, which were held si-
From 7 to 10 October, the

941 exhibitors attending the Motek plus the 115 attending the Bondex present-

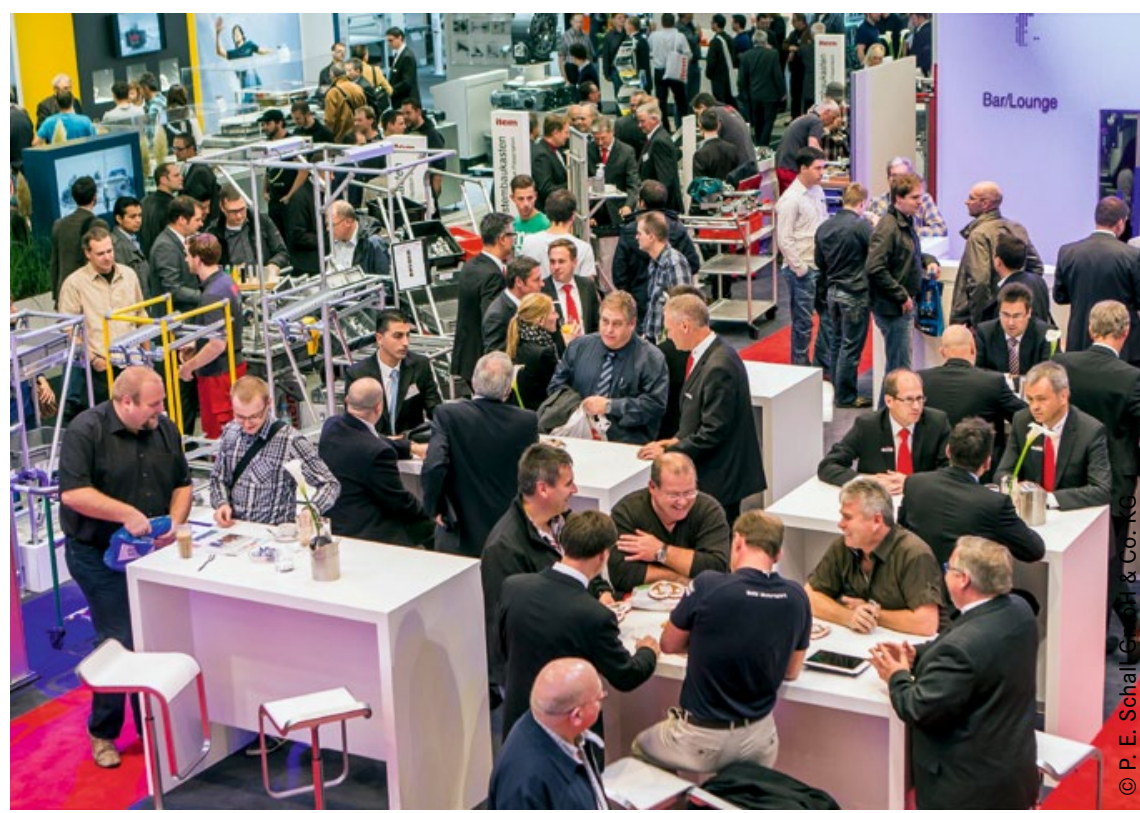

From 7 to 10 October, Messe Stuttgart will focus on production and assembly automation as well as adhesives technology. ed their production and assembly automation solutions and bonding solutions to a total of 36,967 expert visitors from 101 countries.

The strategy of combining all relevant disciplines of production and assembly automation at one central location has obviously been a convincing one for exhibitors and expert visitors again this year: on the one hand, there is the orientation towards portfolio and nomenclature throughout the process chains, and on the other hand there are the bonding-related subjects presented at the Bondexpo. The combination of Motek and Bondexpo is the only specialist event worldwide to cover all segments of production and assembly automation - from components, modules and partial systems / subsystems to complete system solutions.

The 33rd Motek and the 8th Bondexpo are to take place from 6 to 9 October 2014.

\section{3rd edition of Adhesives Technology Compendium published}

The new Adhesives Technology Compendium is now available. This English-language version has been updated for the third time and takes the significance of the German adhesives industry in the global competitive environment into account.

T he worldwide demand for adhesives and sealants "Made in Germany" is as high as ever; the German adhesives industry exports almost one-third of its products every year.

In addition to its top technological position, the German adhesives industry is of great economic significance: with its total yearly production of more than 1.3 million tonnes of adhesives and sealants and almost 1 billion $\mathrm{m}^{2}$ of adhesive film and adhesive tape, the German adhesives industry achieved total revenues of currently approx. $€ 3.4$ billion. The use of these adhesives systems generates a potential added value of more than $€ 350$ billion. This enormous value creation corresponds to approx. $50 \%$ of the contribution of the manufacturing industry and the construc- tion industry to the German gross domestic product (GBP) - or to put it another way:

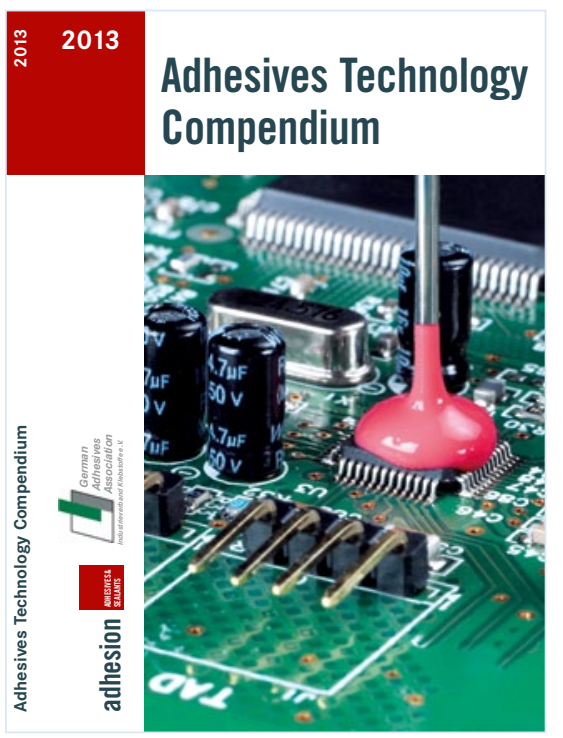

around $50 \%$ of the merchandise produced in Germany is adhesives-related.

The new Adhesives Technology Compendium provides a comprehensive English-language version of the performance and the product range of globally active adhesives suppliers, manufacturers and companies from the fields of equipment, research and services. It also includes important facts on the adhesives industry including the latest legal regulations and European standards as well as test procedures and statistical overviews.

This book has more than 300 pages and facilitates research on the subject of adhesives and sealants. It can be requested by e-mail for a charge of $€ 25.90$ from: adhaesion@springer.com 